\title{
Paving the Way for Future Research in ICT for Governance and Policy Modelling
}

\author{
Fenareti Lampathaki ${ }^{1}$, Yannis Charalabidis ${ }^{2}$, David Osimo ${ }^{3}$, Sotiris Koussouris ${ }^{1}$, \\ Stefano Armenia ${ }^{4}$, and Dimitris Askounis ${ }^{1}$ \\ ${ }^{1}$ National Technical University of Athens, 9 Iroon Polytechniou str., 15780 Athens, Greece \\ \{flamp, skous, askous\} @epu.ntua.gr \\ ${ }^{2}$ University of the Aegean, Karlovassi, 83200 Samos, Greece \\ yannisx@aegean.gr \\ ${ }^{3}$ Tech4i2 ltd., 43B Mill Road, LE7 7JP Thurcaston, Leicestershire, UK \\ david.osimo@tech4i2.com \\ ${ }^{4}$ Sapienza University of Rome, CATTID, P.le Aldo Moro, 5 - 00185 Rome, Italy \\ armenia@cattid.uniroma1.it
}

\begin{abstract}
In light of the contemporary societal challenges and the current technological trends that have revolutionized collaboration and creativity, ICT for Governance and Policy Modelling has recently emerged to achieve a better, participative, evidence-based and timely governance. Bringing together two separate worlds, i.e. the mathematical and complex systems background of Policy Modelling with the service provision, participation and open data aspects in Governance, it has recently gathered significant attention by researchers and practitioners. This paper presents the grand challenges that will inspire research in the domain in the next years, as well as the track from the state of play study, the visionary scenarios building and the gap analysis that has eventually led to their recognition. The specific research challenges target at achieving a collaborative, model-based governance with a strong scientific basis, empowered with data in order to reach collective intelligence, and providing public services as a utility.
\end{abstract}

Keywords: ICT for Governance and Policy Modelling, Grand Challenges, Taxonomy, Research Areas, Model-based Governance, Government Service Utility, Data-powered collective intelligence and action.

\section{Introduction}

Today the world has become increasingly interconnected, complex, and fast-evolving, with the effects of individual behaviour and of policy choices becoming much less predictable. In fact, unpredictability and complexity are two distinguishing characteristics of our society, as widely recognised in the literature about complexity science, chaos theories and non-linear systems. Highly improbable events [26] and "wicked problems" [25], which are outside the range of predictability based on past behaviour, dominate our lives as the recent financial crisis has proven. 
The paradox is that at the same time, the amount of data available for making sense of the socio-economic environment is increasing exponentially, provided through sensors (such as Radio-frequency identification-RFID) and mobile devices, with the help of open government initiatives that have already started to emerge and release public data, or even in bottom-up ways through "crowdsourced" citizens' reports in Social Media. However, governments clearly still struggle to make sense of such large amounts of data and take appropriate action.

With government facing such new and complex problems that cannot be dealt with easily by direct public service provision, more ambitious policies will require more complex interventions and collaboration with non-governmental parties [22]. In this context, 'empowerment' seems to be the next great societal value in response to the massive increases in information, communication and wealth permeating society [4], [23]. According to the new eGovernment Action Plan, by 2015 European public administrations should be "recognised for being open, flexible and collaborative in their relations with citizens and businesses" [19], [27].

Along these ways of evolution, future scenarios in ICT for Governance and Policy Modelling are promising to reach the target of a better, participative, evidence-based and timely governance, while taming greater complexity and attracting citizens' involvement [3]. ICT for Governance and Policy Modelling has emerged as an umbrella term for a number of technologies that can be applied in order to achieve the common goal of improving public decision-making in the age of complexity [8]. They aim at making the policy-making cycle more effective and more intelligent, and at accelerating the learning path embedded in the policy cycle. In recent years we have assisted to a flourishing of ICT tools to support governments in designing policies [5]. However, such tools are not often adopted successfully, also due to fragmentation between academic fields, application areas and approaches to innovation.

In this context, this paper presents the research roadmap related to the domain of ICT for Governance and Policy Modelling, which was created within the CROSSROAD project [9]. CROSSROAD was a FP7 Support Action funded by the European Commission in order to identify and characterize the key research challenges in the domain and ultimately outline a concrete, participative roadmap for future research. Working with expert researchers and practitioners from across Europe, CROSSROAD has consolidated and advanced research in a new, yet highly fragmented, domain by adopting a consensus-driven approach based on collaboration.

The structure of this paper is as follows: Section 2 outlines the methodology followed during the implementation of the roadmap. Section 3 gives an overview of the evolutionary path and the main results that have led to the recognition of the set of the grand challenges. Section 4 finally presents the Grand Challenges, leading to conclusions with the trends and an insight to the benefits of the domain.

\section{Methodology}

In the direction of science and technology roadmapping [11], the approach adopted and described in this paper from a high-level perspective adhered to the principles of openness, iteration, open ended, technology-focused but not technology driven, and beared the following steps: 
- $\quad$ State of Play providing an overview of the state of the art in ICT for Governance and Policy Modelling in terms of research, practice / application, market and policy. A Research Areas Taxonomy has been formulated with the material collected and elaborated in the state of the art analysis in an effort to map for the first time and reach consensus on the diverse domain of ICT for Governance and Policy Modelling.

- Visionary Scenarios "Digital Europe 2030" outlining a set of extreme visionary scenarios on how governance and policy modelling could develop at the horizon 2030. The scenario design was built on two axes (Openness and Transparency, and Integration in Policy Intelligence) that represent the way in which different future societal and policy directions may develop.

- Gap Analysis assessing current developments in ICT for Governance and Policy Modelling and identifying the need for research and technology development (RTD) which is not yet in place through an analysis of the future scenarios.

- $\quad$ Research Roadmap defining a set of Grand Challenges which are understandable, bold and disruptive but strongly rooted in the state of the art and addressable by 2020, while containing significant critical mass of research and inspiring specific Research Challenges. It has raised awareness and created a shared vision that inspires collaborative and interdisciplinary research between academia, business, civil society and government on new research directions in the domain of governance and policy modelling. It has been accompanied by concrete Policy Recommendations and mechanisms on how to define and implement research policy in a complex world.

The proposed roadmap builds on relevant work undertaken in other roadmapping activities produced by other communities on specific application domains related to the ICT for Governance and Policy Modelling domain. Indicative studies that have been studied originate from eGovernment [7], Visual Analytics [15], Personal Health Systems [6], Complex Systems [18], the World Society Modeller [1], the Internet of Things [28] and Cloud Computing [14].

\section{Background}

\subsection{State of Play}

The purpose of the State of the Art Analysis was to provide an overview of the state of the art in ICT for Governance and Policy Modelling in terms of research, practice / application, market and policy [17]. It covered research approaches, practical guidelines and strategic visions that have emerged upon studying the underlying research initiatives, projects, positions, strategies and implementations in a number of technologies which can be applied in order to achieve the target of the better, participative, evidence-based and timely governance.

With the help of a quantitative and qualitative methodology, a Research Areas Taxonomy has been formulated with the material collected and elaborated in the state of the art analysis in an effort to map and reach consensus on the diverse domain of ICT for Governance and Policy Modelling [16]. The taxonomy, which now consists 
of 5 Research Themes (RTs) as broad thematic categories that contain and classify a number of research areas at lower levels, has been discussed and validated by a large set of experts, as well as by relevant EU-funded projects in this domain.

The Research Theme RT.1: Open Government Information \& Intelligence for Transparency appears as the data- and knowledge- oriented research theme. It tries to incorporate next generation light-weight semantic technologies into the Governance and Policy Modelling context by promoting the principles of open data and PSI reuse, as well as the philosophy of linked data and visual analytics.

The Research Theme RT.2: Social Networks, Citizen Engagement and Inclusion infuses the social dimension of the web into Governance and Policy Modelling by investigating the Social Computing phenomenon that has already revolutionized the way people communicate, exchange content and knowledge, raise their opinions and influence each other, by exploiting engagement and eParticipation tools and techniques, and by extracting people's opinion from the web in order to reach collective wisdom.

The Research Theme RT.3: Policy Making, clearly positioned towards ICT-enabled policy making, initially analyzes the economical, social and environmental context as a preparatory stage for policy modelling which then actually represents the problem and its proposed solution. Policy Simulation testing out the various models in an effort to pre-evaluate the application of a specific policy, in a controlled, artificial environment is also studied, while at the last stage in the policy-making process, Policy Evaluation provides the necessary qualitative and quantitative assessment mechanisms to monitor the actual policy application.

The Research Theme RT.4: Identity Management and Trust in Governance is driven by the need to safeguard citizens' and public authorities' digital presence from misuse. In this context, identity management with federated identities, access control and authentication mechanisms in ubiquitous environments, as well as privacy and data protection have proved to contribute in building trust among citizens and public authorities.

The Research Theme RT.5: Future Internet for Collaborative Governance embraces the internet evolution and entails transparent and multichannel service provision via the Internet of Services, low cost cloud infrastructures emerging from Cloud Computing advancements, better human-computer interfaces and seamless interaction with non-conventional web devices that communicate in the Internet of Things.

\subsection{Visionary Scenarios}

The open-ended visionary scenarios developed for Digital Europe 2030 aimed at defining a set of scenarios on how governance and policy modelling, supported and enhanced by the use of Information and Communication Technologies (ICTs), could develop by 2030 in order to identify the research needs and policy challenges to be addressed [21]. The scenarios are internally consistent views of what the European governance and policy making system could become by 2030 and of what the resulting implications for citizens, business and public services would be. The uncertainties underlying the scenario design are: 1) the societal value system we will be living in (more inclusive, open and transparent or exclusive, fractured and restrictive), and 2) the response (partial or complete, proactive or reactive) to the acquisition and integration of policy intelligence techniques in support of data processing, modelling, visualization and simulation for evidence-based policy making. 
A framework for the analysis of current and future challenges in ICT for governance and policy Modelling has been drawn. Accordingly, the key impact dimensions were classified on two axes: Openness and Transparency and Integrated Policy Intelligence [20]. The following four scenarios were defined according to their positions on the two axes of the scenario design framework:

- Open governance: characterized by high openness and transparency and high integration in policy intelligence;

- Leviathan governance: characterized by low openness and transparency and high integration in policy intelligence;

- Privatised governance: characterized by low openness and transparency and low integration in policy intelligence;

- Self-service governance: characterized by high openness and transparency and low integration in policy intelligence.

\subsection{Gap Analysis}

Gap analysis aimed at comparing the present status of ICT for Governance and Policy Modelling presented in the state-of-the-art analysis and the future needs of ICT for Governance and Policy-Modelling depicted through the visionary scenarios. Taking into account that a gap expresses both mismatches between the state of play and the future scenarios, as well as lacks of current research identified in the scenarios [2], the gap analysis aimed at identifying specific gaps in the domain of Governance and Policy Modelling, i.e. the missing elements to realize the most desirable scenarios; and the elements of the current situation that could lead to the realization of the less desirable scenarios.

The gap analysis collaborative process resulted in 42 gaps: 6 gaps within RT1, 9 gaps within RT2, 11 gaps - RT3, 7 gaps - RT4, 5 gaps - RT5 and 4 gaps stemming from visionary scenarios. All gaps were assessed regarding their relevance and impact on the main principles of Good Governance (openness, participation, accountability, effectiveness and coherence) [13], while a cross analysis of relations between and classifications of gaps was introduced in order to depict their interrelations.

\section{Crossroad Grand Challenges}

In order to provide strategic directions for the future of research in the domain of ICT for Governance and Policy Modelling, consensus was reached through online and offline brainstorming and validation workshops on a limited number of Grand Challenges [10]. Such challenges present the following features: are understandable, visual and inspire research ideas; are bold and disruptive but strongly rooted in the State of the Art and addressable by 2020; contain significant critical mass of research; and address gaps across multiple Research Themes.

In particular, in order to grasp the opportunities that emerge from the current trends and to lead to a paradigm shift in policy-making, the following Grand Challenges have to be met: 
- GC1 - Model-based collaborative governance: How to assist policy makers in taking evidence-based decisions in our complex, unpredictable world? Existing econometric models are unable to account for human behaviour and unexpected events. New policy modelling and simulation are fragmented, single-purposed and work at micro-level. There is a need for robust, intuitive, reusable collaborative modelling tools that can be integrated into daily decision-making processes.

- GC2 - Data-powered collective intelligence and action: How can we make sure that increased transparency translates into actual more open and more effective policy-making? Current tools require high involvement and attention, therefore engaging only the very committed people. They are designed to facilitate conversations, rather than action. There is a clear need for more intuitive collaborative tools that are able to engage also less interested people, maximizing the impact of short attention span and lowengagement, as well as for ICT based feedback mechanism that are able to encourage real action and behavioural change.

- GC3 - Government Service Utility: How to provide high-impact services to citizens, businesses and administrations in a way that allows for co-design, public-private collaboration, citizen interaction and service co-generation that allows for 1-stop, 1-second service delivery at very low cost and administrative burden and for completely new services, through mash-ups and interoperability-by-design?

- GC4 - Scientific base of ICT for Governance and Policy Modelling: How to make ICT-enabled governance a rigorous scientific domain, by providing formal methods and tools? The systematic classification of problems and solutions and description through formal languages, in an effort to make diagnosis and prescription of solutions a scientific process that will allow building on top of existing knowledge.

These challenges can be depicted as three key pillars crowned by the fourth overarching challenge in the adapted 'stagist' model of the policy process [12] and the management cycle, as illustrated in the figure below.

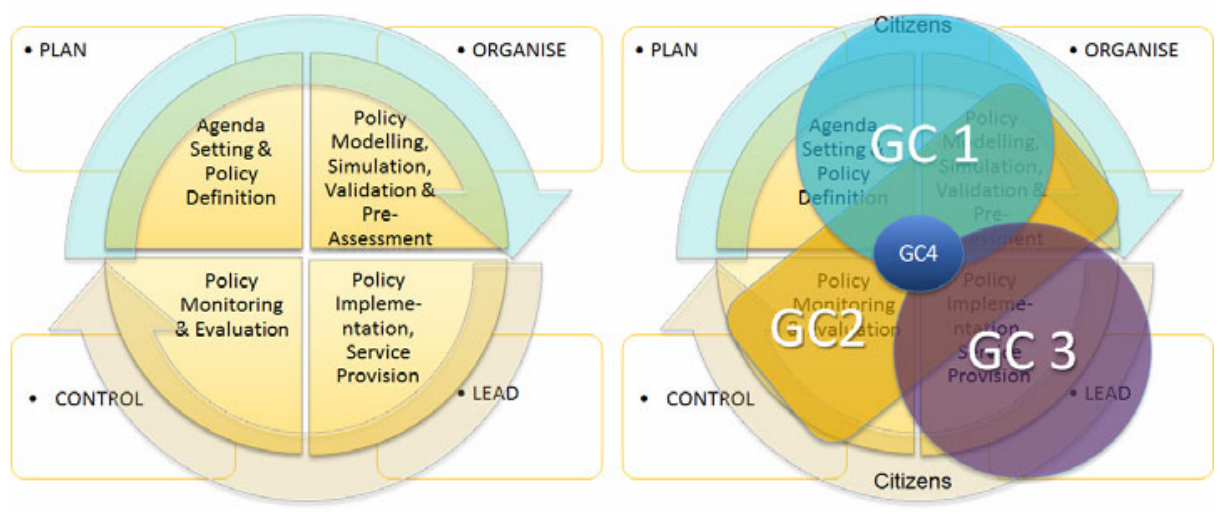

Fig. 1. CROSSROAD Grand Challenges in the Policy Making Cycle 


\subsection{Model-Based Governance}

Our rapidly changing and complex society requires an efficient and effective decision-making process, able to anticipate future events, promptly detecting emergencies and evaluating the impact of different policy choices, reflecting the reallife complexity while making it simpler and addressable. The GC1 Model-based Collaborative Governance focuses on the development of advanced tools and methodologies in order to pursue the above-mentioned goals. It follows a vision of a radically different context for policy modelling and simulation, where standardisation and reusability of models and tools, system thinking and modelling applied to policy impact assessment has become pervasive throughout government activities. GC1 aims at enabling the engagement of all stakeholders (even without expert skills) in collaborative policy model building, simulation and evaluation process. This implies a great effort to improve state-of-the-art ICT tools and methodologies in order to guarantee the efficiency of policy modelling process. The improvements, in terms of usability and consequently time and cost consumption, the effectiveness of the process as well as in terms of reliability and knowledge of both models and policies should be introduced.

In this context, the research challenges that should be addressed with a long-term perspective include:

- RC1.1: Integrated, composable and re-usable models to create more comprehensive and complex models by using smaller building blocks or existing objects/models. This implies both model interoperability and the definition/identification of proper modelling standards, procedures and methodologies.

- RC1.2: Collaborative modelling encompassing participation of all stakeholders in the policy-making process through the implementation of Internet-based easy-to-use tools for all the levels of skills.

- RC1.3: Easy access to information and knowledge creation with a particular focus on elicitation of information which, in turn, during the overall model building and use processes will help decision makers to learn how a certain system works and ultimately to gain insights and understanding in order to successfully implement a desired policy.

- RC1.4: Model validation in order to guarantee the reliability of models and, consequently, of policies that are crucial for policy makers who need and use information that results from the simulations to develop more effective policies.

- RC1.5: Interactive simulation concentrating on the fact that the larger is the model in terms of size and complexity, the larger is the resulting amount of data to analyse and visualize. In particular, this challenge refers to the issue of integration of visualisation techniques within an integrated simulation environment, in order to dramatically increase the efficiency and effectiveness of the modelling and simulation process, allowing the inclusion and automation of some phases (e.g. the output and feedback analysis) that were not managed in a structured way up to this point. 
- RC1.6: Output analysis and knowledge synthesis refers to output analysis of a policy model and, at the same time, to feedback analysis in order to incrementally increase and synthesise the knowledge of the model (and consequently of the policy).

\subsection{Data-Powered Collective Intelligence and Action}

The current citizen participation scene is characterised by an engagement of highly interested people only, and by an engagement that rarely stimulates genuine action. There are several complementary research areas in ICT for governance and policy modelling which have the opportunity to address the need for collaboration and behavioural change throughout different technological layers: enhanced data availability through public linked data and participatory sensing, analytical capability through opinion mining and visual analytics, and action-oriented tools such as simulation and serious gaming. These trends mutually reinforce each other to offer a new opportunity for future ICT for governance and policy modelling.

The collaborative governance vision, proposed as an alternative, includes citizens in all the phases of the governance: in collecting relevant data through participatory sensing tools; in analysing the data through simulation and visualisation software; in acting upon these data through bottom-up self-organized action which accompanies, anticipates and stimulates government policies.

For this vision to become a reality, substantial research effort is needed in following research challenges:

- RC2.1: Privacy-compliant participatory sensing for real-time policy-making refers to the use of sensors, usually embedded in personal devices such as smartphones allowing citizens to appropriately feed data of public interest.

- RC2.2: Real-time, high-quality, reusable open government data calls for simplification and lower costs of open data publication.

- RC2.3: Federated dynamic identity management addresses the eIdentityrelated issues for secure public service provision, citizen record management and law enforcement.

- RC2.4 Peer-to-peer public opinion mining points out to the explosion of user-generated content, which widens the application scope of public opinion mining tools and to the fact that these tools need to become more pervasive and available to the majority of citizens.

- RC2.5: Intuitive, collaborative visual analytics of data for policy-making refers to the research focused on making sense of large datasets, such as those provided as open government data.

- RC2.6 User-generated simulation and gaming tools for public action underlines that serious gaming is still requiring high level of engagement and, therefore, progress in usability and attractiveness in order to widen the group of participants is needed.

- RC2.7: New institutional design of collaborative governance recalls that collaborative governance is developing without an appropriate reference framework. 


\subsection{Government Service Utility}

The dawn of a new era which highlights service creation and delivery as its principal ingredient has started to influence the public sector that now needs to drive public services towards Future Internet advancements. The Grand Challenge GC3Government Service Utility has adopted the key concepts of a utility [24], such as Ubiquitous nature, Usability, Federation, Co-generation, and De-regulation, and is aligned to the philosophy of collaboration, openness and innovation. According to the our vision, it aims to cultivate "... a vision of the Internet of the Future, where public organisations, citizens, enterprises and non-profit organisations can collaboratively shape public services at design-time and runtime, in order to be delivered as a utilitylike offering at their own ends, to the channels they prefer and in the context and situation they are".

In this context, the research challenges that should be addressed in the long-term perspective include:

- RC3.1: User-driven innovation shaping Public Services during their whole lifecycle in order to be delivered to their beneficiaries at their own ends, in ways and means they prefer.

- RC3.2: Change the DNA of Public Services in the direction of the 1-1-1 concept that supposes that «Every public service can be provided in onestop, within one second, with one euro (or minimum) cost, to any device and by anything».

- RC3.3: Digital Public Services Value Proposition for All which defines and assesses the impact for all stakeholders within a complex public services ecosystem.

- RC3.4: Massive Public Information as a Service promoting a serviceoriented attitude to the public sector information (PSI).

\subsection{Science Base of ICT for Governance and Policy Modelling}

The general aim of GC4 is to establish the initial foundation of ICT for Governance and Policy Modelling as a new science, complementing those of Informatics and Political Science, which is envisaged to benefit from all developments of the neighbouring field. It encompasses the following Research Challenges:

- RC4.1: Multidisciplinary issues and relations with neighbouring domains, that investigates possible links with other scientific areas and attempts to structure the domain according to other successful domains.

- RC4.2: Metrics and Assessment Models, Decision Support, Modelling \& Simulation Tools, that aim to bring together the technological and the societal aspects of the domain of ICT for governance and policy modelling towards more concrete, holistic and accurate decision support models.

- RC4.3: Formal methods and tools, which aim at the setting the foundations for the new proposed scientific domain. 


\section{Conclusions}

A paradigm shift in the nature and quality of policy-making is emerging based on three complementary disruptive techno-economic trends: the explosion in the quantity of data available; the proactive role assumed by citizens in contributing to the policymaking process, by authoring and elaborating the data increasingly made available; and the advanced capabilities, affordability and accuracy of simulation and modelling techniques. ICT tools have the potential to effectively support policy modelling and governance and their use is growing continuously even if they still remain a "novelty" for the majority of governments. The already acknowledged benefits for their use by governments lie on the quality and speed of policy making, as well as on the evidence-based policy decision making [10].

In order to outline future research directions in the domain of ICT for Governance and Policy Modelling, the present paper has described a methodology that creates a shared vision, able to inspire collaborative and interdisciplinary research, and between academia, business, civil society and government. Upon studying the state of the art advancements in the domain, envisioning future, disruptive scenarios on how society will evolve in 2030 and analyzing the gaps, a set of concrete grand challenges that bundle together specific research challenges has been identified. The proposed grand challenges that have been validated by a large number of experts (in online workshops and face-to-face events) include the Model-based Governance (GC1), Data-powered collective intelligence and action (GC2), Government Service Utility (GC3) and Science Base of ICT for Governance and Policy Modelling (GC4).

Acknowledgments. This work has been created in the context of the EU-funded Support Action CROSSROAD (A Participative Roadmap for ICT Research in Electronic Governance and Policy Modelling), Contract No: FP7-ICT-248484. It has been also supported by the EU-funded project GIC - Greek Interoperability Centre (Contract No: FP7-204999).

\section{References}

1. Badii, A.: World Society Modeller (S Gaia), FET Flagship Proposal within the FutureIcT stream, pp. 6-13 (2010), http://cordis.europa.eu/fp7/ict/fetproactive/docs/flagshipcons09-01_en.pdf

2. Bicking, M., Wimmer, M.: Concept to Integrate Open Collaboration in Technology Roadmapping: Stakeholder Involvement in Strategic E-Government Planning. In: Proceedings of the 44th Hawaii International Conference on System Sciences (HICSS), Hawaii, USA (2011)

3. Botterman, M., Millard, J., Horlings, E., van Oranje, C., van Deelen, M., Pedersen, K.: Value for citizens-A vision of public governance in 2020, European Commission (2008)

4. Broster, D., Cachia, R., Centeno, C., Kluzer, S., Lindmark, S., Lusoli, W., et al.: The Impact of Social Computing on the EU Information Society and Economy (2406 3rd ed.). European Commission JRC IPTS (2009), doi: 10.2791/29872

5. Charalabidis, Y., Koussouris, S., Kipenis, L.: Report on the Objectives, Structure and Status of eParticipation Initiative Projects in the European Union, MOMENTUM White Paper (2009) 
6. Codagnone, C.: Reconstructing the Whole: Present and Future of Personal Health Systems Roadmapping Personal Health Systems: Scenarios and Research Themes for Framework (2009),

http://ec.europa.eu/information_society/activities/health/doc s/projects/phs2020/phs2020-book-rev16082009.pdf

7. Codagnone, C., Wimmer, M.A.: Roadmapping eGovernment Research - Visions and Measures towards Innovative Governments in 2020, Results from the EC-funded Project eGovRTD2020 (2007)

8. Consultation report on ICT for Governance and Policy Modelling. FP7 Work Programme 2011-2012 (February 2010),

http: / / ec.europa.eu/information_society/activities/egovernmen t/research/fp7/docs/consultation_report_feb2010.pdf

9. CROSSROAD Project (2011), http: / / www. crossroad-eu . net

10. CROSSROAD, D4.3 Final Roadmap (December 2010), http://crossroad.epu.ntua.gr/files/2010/02/CROSSROAD_D4.3_Fin al_Roadmap_Report-v1.00.pdf

11. Da Costa, O., Boden, M., Friedewald, M.: Science and Technology Roadmapping for Policy Intelligence: Lessons for Future Projects, European Commission, JRC-IPTS (2003)

12. Easton, D.: A Framework for Policy Analysis. Prentice-Hall, Englewood-Cliffs (1965)

13. EC: European Governance - A White Paper, COM 428 final (2001)

14. Jeffery, K., Neidecker-Lutz, B. (eds.): The Future of Cloud Computing, Opportunities for European Cloud Computing Beyond 2010 (2009),

http: //cordis.europa.eu/fp7/ict/ssai/docs/cloud-reportfinal.pdf

15. Keim, D., Kohlhammer, J., Ellis, G., Mansmann, F. (eds.): Mastering the Information Age: Solving Problems with Visual Analytics. Eurographics Association (2010)

16. Lampathaki, F., Charalabidis, Y., Passas, S., Osimo, D., Bicking, M., Wimmer, M.A., Askounis, D.: Defining a Taxonomy for Research Areas on ICT for Governance and Policy Modelling. In: Wimmer, M.A., Chappelet, J.-L., Janssen, M., Scholl, H.J. (eds.) EGOV 2010. LNCS, vol. 6228, pp. 61-72. Springer, Heidelberg (2010)

17. Lampathaki, F., Koussouris, S., Charalabidis, Y., Askounis, D., Mouzakitis, S., Passas, S., Tsavdaris, H., Osimo, D., De Luca, A., Armenia, S., Bicking, M., Wimmer, M., Misuraca, G.: State of the Art in "ICT for Governance and Policy Modelling". In: Lampathaki, F., Koussouris, S., Charalabidis, Y., Askounis, D. (eds.) CROSSROAD White Paper (2010)

18. Living Roadmap of Complex Systems, RNSC (2008),

http: / / css.csregistry.org/tiki-index .php?page=Living+Roadmap

19. Ministerial Declaration on EGovernment approved unanimously in Malmö, Sweden (2009), http://www.se2009.eu/polopoly_fs/1.24306menu/standard/file/Mi nisterial\%20Declaration\%200n\%20 eGovernment.pdf

20. Misuraca, G., Broster, D., Centeno, C.: Envisioning Digital Europe 2030: Scenario design on ICT for governance and Policy Modelling. In: Proceedings of the 4th International Conference on Theory and Practice of Electronic Governance (ICEGOV 2010). ACM International Conference Proceedings Series, pp. 347-356. ACM Press, New York (2010)

21. Misuraca, G., Broster, D., Centeno, C., Punie, Y., Lampathaki, F., Charalabidis, Y., Askounis, D., Osimo, D., Szkuta, D., Bicking, M.: Envisioning Digital Europe 2030: Scenarios for ICT in Future Governance and Policy Modelling. In: Misuraca, G., Lusoli, W.W. (eds.) IPTS JRC Scientific and Technical Reports. EUR 24614 (2010)

22. OECD: Modernising Government: the way forward, OECD, Paris (2005) 
23. Osimo, D.: Government 2.0 - Hype, Hope, or Reality? European Journal of ePractice, 9 (2010)

24. Rappa, M.A.: The utility business model and the future of computing services. IBM Systems Journal 43(1), 32-42 (2004)

25. Rittel, H., Webber, M.: Dilemmas in a General Theory of Planning, Policy Sciences, vol. 4, pp. 155-169. Elsevier Scientific Publishing Company, Inc., Amsterdam (1973)

26. Taleb, N.N.: The Black Swan: The Impact of the Highly Improbable. Penguin (2008)

27. The European eGovernment Action Plan 2011-2015 - Harnessing ICT to promote smart, sustainable \& innovative Government, COM, 743 (2010)

28. Vermesan, O., Harrison, M., et al.: Internet of Things. Strategic Research Roadmap (2009), http://ec.europa.eu/information_society/policy/rfid/documents / in_cerp.pdf 